\title{
ANÁLISE COMPORTAMENTAL DA CULTURA: CONTINGÊNCIA OU METACONTINGÊNCIA COMO UNIDADE DE ANÁLISE?
}

\author{
BEHAVIORAL ANALYSIS OF CULTURE: CONTINGENCY OR METACONTINGENCY AS THE UNIT OF \\ ANALYSIS?
}

UNIVERSIDADE ESTADUAL PAULISTA (UNESP), BRASIL

Kester CARRARA

DIEGO ZILIO

UNIVERSIDADE FEDERAL DO ESPÍRITO SANTO, BRASL

\begin{abstract}
RESUMO
O objetivo deste artigo é avaliar o caráter de inovação e o alcance explicativo do conceito de metacontingência como instrumento de análise da cultura, quando comparado à contingência de três termos. São levados em consideração conceitos associados, como os de contingências entrelaçadas, produto agregado e sistema receptor, para um cotejamento de funcionalidade quando em comparação com a clássica contingência de três termos. Conclui-se que, apesar da contribuição relevante estruturada por Glenn e colaboradores, o "sistema de metacontingências" equivale a um rearranjo conceitual dos princípios presentes na proposição skinneriana de análise comportamental da cultura, que também pode ser viabilizada mediante o uso do conceito de contingência, se criteriosamente descritas as condições de cada elemento envolvido nas práticas culturais e seu entorno.
\end{abstract}

Palavras-chave: Seleção por consequências; Metacontingência; Contingência; Análise comportamental da cultura; Behaviorismo radical.

Our goal in this paper is to discuss the novelty character and explanatory range of metacontingency in relation to the three-term contingency. Auxiliary concepts, as interlocking behavioral contingencies, aggregate product and receiving system, were also taken into account in evaluating metacontingency's functionality in comparison with the three-term contingency. We conclude that, besides Glenn's and her collaborators relevant contribution to the field, the "metacontingency system" is nothing more than a conceptual rearrangement of the principles present in Skinner's proposal for the analysis of culture, which can be fashioned solely through the concept of contingency when the conditions of the elements involved in cultural practices are carefully described. behaviorism.

Keywords: Selection by consequences; Metacontingency; Contingency; Behavioral analysis of culture; Radical

Os autores agradecem ao CNPq e à FAPESP pelo apoio mediante Bolsa de Produtividade em Pesquisa ao primeiro autor (Proc. 305405/2011-0) e Bolsa de Pós-Doutorado ao segundo (Proc. 2013/17950-1). Correspondência para: kestercarrara@,cnpq.pq.br 
Elas [a espécie e a cultura] estão "além do indivíduo", no sentido de serem responsáveis por ele e de sobreviver a ele. Entretanto, uma espécie não tem existência em separado da de seus membros; nem uma cultura tem existência em separado daquela das pessoas que a praticam. É somente pelos efeitos nos indivíduos que as práticas são selecionadas ou planejadas. (Skinner, 1969/1984a, p. 212)

Desde seus primeiros escritos, B. F. Skinner revela interesse na explicação descritiva das origens e desenvolvimento das relações entre organismos e ambiente. Dois de seus livros seminais (cf. Fantino, 1988; Marr, 2003), O comportamento dos Organismos, de 1938, e Ciência e Comportamento Humano, de 1953, concretizam esse interesse mediante: (1) a formulação de princípios essenciais para a descrição e explicação das relações funcionais entre as atividades do organismo, especialmente no âmbito do comportamento operante, que possam ser devidamente enquadradas como "comportamento" no âmbito de contingências comportamentais e os eventos ambientais antecedentes e consequentes; (2) a apresentação de numerosos exemplos de comportamentos produzindo consequências sob condições contextuais várias, configurando um consagrado instrumento conceitual de análise cunhado pelo autor como contingência.

Ocorre, no entanto, que os arranjos possíveis assumem extensa diversificação, considerada (ainda com ênfase no operante) a variabilidade de condições antecedentes (contexto), comportamentos e acontecimentos subsequentes no âmbito da contingência de três termos proposta por Skinner. Em função do cânone científico que valoriza a escolha de delineamentos experimentais simples (não no sentido de simplistas, mas "elegantes" metodologicamente) a pesquisa básica privilegia aspectos singulares a serem manipulados como variáveis independentes. Tal elegância deve garantir eficiência no controle de variáveis estranhas e, ao mesmo tempo, deve assegurar a descrição acurada de eventuais relações de dependência entre variáveis (independentes e dependentes) relevantes para os objetivos temáticos investigados. $\mathrm{O}$ fato de que se adote um modelo explicativo "econômico" não significa, no entanto, que desse modelo não possam ser deduzidas como necessárias outras medidas derivadas a partir dele. Nesse sentido, resulta evidente que a contingência de três termos é um modelo paradigmático (e, aparentemente, o mais "enxuto" possível) de análise do comportamento diante de condições antecedentes circunstancialmente dadas e condições subsequentes (que, em tese, serão consequentes) especificadas. A saber, apesar da frequência com que foram desenvolvidos na Análise do Comportamento experimentos utilizando estímulos discriminativos como "eventos antecedentes", não são apenas esses eventos discretos que podem participar, propriamente, de um contexto antecedente. Nele podemos encontrar uma operação estabelecedora, por exemplo. Teríamos, então, uma quarta instância? Uma contingência de quatro termos? Não exatamente. De fato, trata-se da identificação e controle experimental de mais uma instância do âmbito do contexto antecedente (o qual, ele todo, continuaria sendo o primeiro termo) e, nesse sentido, a contingência (como unidade fundamental de análise) continuaria sendo de três termos. Estes aludem a três ocorrências distintas, paradigmáticas no sentido de que constituem a própria essência lógica da seleção pelas consequências na Análise do Comportamento, dispostas numa sequência temporal específica: o que acontece antes, o comportamento, e o que acontece depois deste.

Nas palavras de Skinner (1969/1984a):

Uma formulação das interações entre um organismo e o seu meio ambiente, para ser adequada, deve sempre especificar três coisas: (1) a ocasião na qual ocorreu a resposta, (2) a própria resposta e (3) as consequências reforçadoras. As relações entre elas constituem as "contingências de reforço". ... O comportamento gerado por um conjunto dado de contingências pode ser considerado cientificamente, sem que se tenha de apelar para estados ou processos internos hipotéticos. (p. 182)

Cada termo, por sua vez, sempre exige um trabalho descritivo preciso. No caso dos antecedentes, a literatura tem consolidado muitas pesquisas que corroboram um quarto ou quinto termo dessa relação, a partir de Sidman (1986). Nesse sentido, embora a rigor mantido o paradigma de três termos, o primeiro deles (contexto antecedente) revela a possibilidade, por exemplo, de identificação de relações estímulo-estímulo precedentes às relações do tipo estímulo antecedentereposta-consequência. Conforme apontou Sidman (1986): "Aqui, a relação estímulo-resposta abre oportunidade para uma relação estímulo-estímulo: os estímulos condicionais não controlam as respostas diretamente, mas determinam o controle que outros estímulos exercem sobre a resposta" (p. 225). Contribuições importantes sobre a maneira pela qual aspectos específicos do contexto antecedente, no sentido dado, afetam comportamentos e "reconfiguram" a contingência de três termos podem ser encontradas em De Rose (1993), Lopes Jr. e Matos (1995), e Souza (1997).

Observe-se, especialmente - uma vez que o que está em pauta neste artigo é um eventual cotejamento entre contingência e metacontingência (ou a análise de eventual complementaridade entre essas unidades) - que o cenário de pesquisas em equivalência de estímulos, conquanto explore instâncias adicionais ao primeiro termo, preserva claramente a articulação suficiente entre os clássicos três termos. $\mathrm{O}$ avanço significativo dessa área de investigação não requereu, para além de uma explicitação do detalhamento do contexto, a adoção de um novo paradigma das relações funcionais estudadas pela Análise do Comportamento no âmbito da cultura. Nesse sentido, em que medida a proposição do conceito de metacontingência se caracteriza na mesma direção ou, em contraposição, sugere que o caso específico da análise comportamental da cultura requer que seja considerada como nova unidade de análise?

\section{Skinner e a interpretação operante das contingências culturais}

Quase invariavelmente, retomar Skinner favorece encontrar pistas para a maioria das questões teóricas do comportamentalismo por ele formulado. $\mathrm{O}$ autor já havia 
produzido mais de 60 publicações (incluindo artigos e os livros O Comportamento dos Organismos e Walden Two) quando começa a divulgar, sistematicamente, em Ciência e Comportamento Humano (1953/1967) suas reflexões sobre o comportamento das pessoas em grupo. Adquirira, em pouco mais de 20 anos de carreira, uma experiência importante na condução de pesquisa básica e, muito provavelmente, já refletira extensamente sobre as implicações para a espécie humana dos seus achados na Análise do Comportamento. O fato de seu segundo livro publicado (Walden Two, de 1948) ser uma novela utópica sobre uma comunidade criada a partir dos fundamentos comportamentalistas, incluindo-se a análise do comportamento social, representa evidência relevante que sugere essa preocupação do autor. Não deixa de ser pertinente ressaltar também que essa mesma obra foi a principal fonte de controle do comportamento de Glenn ao propor pela primeira vez o conceito de metacontingência em 1986.

Em Ciência e Comportamento Humano (Skinner, 1953/1967) o autor apresenta interpretações do comportamento das pessoas em grupo a partir do que já se sabia sobre o operante em decorrência de dados experimentais. Ao termo "interpretação" deve-se atribuir significado específico: interpretar é usar os "termos e princípios científicos ao discorrer sobre fatos a respeito dos quais pouco se sabe para tornar a predição e o controle possíveis" (Skinner, 1984/1988, p. 207). Em outras palavras, Skinner utilizou-se das leis e conceitos criados a partir da análise experimental do comportamento para interpretar fenômenos que, ao menos no momento, não eram passíveis de controle experimental. Já devidamente consagrado na análise do comportamento, o conceito de operante aparece em três seções de natureza interpretativa (IV, V e VI, totalizando oitenta páginas - 171-250 na edição consultada) dedicadas a: $O$ comportamento das pessoas em grupo, Agências controladoras e $O$ controle do comportamento humano. O autor é, desde logo (p. 171) contundente quanto à possibilidade de existência de qualquer diferença de natureza entre operantes comumente emitidos em situações discretas de interação individual e o que se designa como comportamento social na Análise do Comportamento:

O comportamento social pode ser definido como o comportamento de duas ou mais pessoas uma em relação à outra ou destas, em conjunto, em relação ao ambiente comum. Com frequência se argumenta que é diferente do comportamento individual e que há "situações sociais" e "forças sociais" que não podem ser descritas na linguagem da ciência natural. Diz-se que se requer uma disciplina especial denominada "ciência social" por causa da aparente ruptura na continuidade da natureza. ... uma "lei social" deve ser gerada pelo comportamento de indivíduos. É sempre o indivíduo que se comporta e que se comporta com o mesmo corpo e de acordo com os mesmos processos usados em uma situação não social. ... O comportamento do indivíduo explica o fenômeno do grupo. ... Preocupamo-nos aqui simplesmente com a extensão em que uma análise do comportamento do indivíduo, que já recebeu substancial validação sob as condições favoráveis de uma ciência natural, pode contribuir para o entendimento dos fenômenos sociais.
Aplicar nossa análise aos fenômenos do grupo é um modo excelente de testar sua adequação, e se formos capazes de explicar o comportamento de pessoas em grupos sem usar nenhum termo novo ou sem pressupor nenhum novo processo ou princípio, teremos demonstrado uma promissora simplicidade nos dados. ... O comportamento social surge porque um organismo é importante para outro como parte de seu ambiente. (Skinner, 1953/1967, pp. 171-172, itálicos adicionados)

Os trechos italicizados na citação demonstram a coerente preocupação de Skinner com a preservação de seu sistema explicativo, reafirmando ser desnecessária a adição de conceitos apoiados em dimensão diversa daquela em que o comportamento está sendo explicado, como já o fizera em Are theories of learning necessary? (Skinner, 1950). Adiante, o autor (1953/1967) reafirma que, mesmo na situação de grupo, "é sempre o indivíduo que se comporta" (p. 178), o que não invalida a constatação de que o grupo (de fato, mais precisamente $o s$ indivíduos na situação de grupo) "tem o efeito mais poderoso" (p. 179). Com essas ressalvas, Skinner sinaliza que as consequências, mesmo sob o sincronismo inerente à participação comunitária de indivíduos em grupos com diferentes finalidades e características, afetam o comportamento individual. É evidente que, de maneira diferente do que nas relações discretas do indivíduo com seu ambiente particular, na situação coletiva e social os padrões comportamentais são concatenados e mediados, exigindo, em muitos casos, uma sequência de condicionalidades (por exemplo, uma contingência na qual a consequência, comum a todos do grupo, pode depender de que, diante de um contexto antecedente dado, "a" faça "X", "b" faça "Y" e "c" faça " $Z$ ", necessariamente nessa ordem e numa sequência temporal e topografia especificadas). Essa sequência - e unicamente ela garantiria determinado tipo de consequência. Assim configurados, os comportamentos individuais geram uma consequência "coletiva", ou seja, igual ou equivalente para todos ou uma parcela dos participantes. Todavia, cada qual dos componentes recebe aludida consequência e não, propriamente, o grupo, já que grupo não é organismo e, nessa perspectiva, não se comporta. Ainda com Skinner (1969/1984a): "Uma cultura bem planejada é um conjunto de contingências de reforço sob o qual os membros se comportam de acordo com procedimentos que mantêm a cultura, capacitam-na a enfrentar emergências e modificam-na de modo a realizar essas mesmas coisas mais eficientemente no futuro". (p. 207, itálicos adicionados)

Note-se que nessa passagem Skinner define cultura como "conjunto de contingências de reforço"; especificamente, "cultura" (no texto de 1953), configurase como um conjunto de contingências sociais mantidas pelos membros de um grupo. Um indivíduo faz parte de uma "cultura" se as contingências sociais que a caracterizam possuírem alguma função no controle de seu comportamento, de maneira que a análise da cultura consiste em análise de contingências sociais que mantêm o comportamento dos indivíduos em situação de grupo. 
Em diversas publicações posteriores a Ciência $e$ Comportamento Humano (1953/1957), Skinner faz referências diretas à cultura como objeto de uma análise comportamental (1961, 1966, 1969/1984a, 1978, 1986, por exemplo). No entanto, não chega a desenvolver "experimentos culturais", embora analise extensamente práticas culturais e as contingências que as descrevem (cf. 1953/1967 e 1961). Em contrapartida, numerosas pesquisas aplicadas e intervenções no âmbito de comunidades têm sido desenvolvidas tendo como base a clássica contingência de três termos (e.g., Barrish, Saunders \& Montrose, 1969; Bushell, Wrobel \& Michaelis, 1968; Coyne, 1978; Lloyd, Eberhardt \& Drake, 1996; McMichael \& Corey, 1969; McSweeny, 1978; Pigott, Fantuzzo \& Clement, 1986; Zimmerman, Zimmerman \& Russell, 1969).

\section{A metacontingência e a suposta insuficiência da contingência}

A priorização de intensa e extensa pesquisa básica liderada por Skinner concorreu para que uma estratégia típica de emprego da contingência de três termos não se consagrasse no âmbito da análise e planejamento cultural. As pesquisas sobre comportamento social (tais com as mencionadas anteriormente) e práticas culturais continham estratégias metodológicas bastante diversificadas, a depender de seus objetivos. Esse cenário parece ter controlado $\mathrm{o}$ envolvimento de vários pesquisadores com duas vertentes temáticas que, na maior parte das vezes, fizeram intercâmbio: a que polarizava a militância em busca de uma sociedade mais equânime (e que gerou iniciativas como a criação do periódico Behaviorists for Social Action, cuja continuidade se dá, atualmente, pelo Behavior and Social Issues) e a que buscava viabilizar a ampliação de aplicações práticas da Análise do Comportamento a problemas sociais pontuais. Nesse âmbito, especialmente nas décadas de 1980/1990, foram veiculadas publicações questionadoras (Holland, 1974), coletâneas de textos sobre questões sociais sob o ângulo comportamentalista (Lamal, 1991, 1997) e, sobretudo, proposições altamente relevantes para uma caracterização e sistematização de procedimentos de análise comportamental da cultura (Glenn, 1986, 1988, 1991, 2003a, 2003b, 2004; Glenn \& Malott 2004a, 2004b, 2004c, 2004d, 2004e, 2004f, 2004g, 2005).

O trabalho de Sigrid Glenn, particularmente, constitui-se em relevante contribuição para o esclarecimento da lógica funcional das práticas culturais e, especialmente, para o estabelecimento de diferenças funcionais entre estas e os comportamentos individuais. A contribuição de Glenn se dá a partir da proposição do conceito de metacontingência (1986) e da formulação de outras instâncias (produto agregado, contingências entrelaçadas, sistema receptor, consequências culturais) que considera imprescindíveis para uma análise comportamental da cultura. Como esclarecem Glenn e Malott (2004a) em resposta a Salzinger (2004), analisando a produção científica de um grupo de pesquisa na universidade:
A diferença entre a abordagem de Salzinger e a nossa reside no objeto de estudo. Organizações são coisas distintas do comportamento individual - elas requerem objetos distintos de estudo. Se o nosso foco de estudo é o comportamento de um organismo, poderíamos compreendê-lo pela análise das contingências que ocasionam aquele comportamento. Mas se o nosso foco é o desempenho de uma organização, as contingências operantes são insuficientes para compreender a sua natureza. Precisamos avaliar os produtos agregados e o conjunto de interconexões que geram esses produtos. Não estamos simplesmente interessados em aumentar a produtividade de um pesquisador individual. Ao invés disso, estamos preocupados em melhorar a produtividade da universidade como um todo. (pp. 143-144)

O trecho citado revela a distinção feita pelas autoras em relação a objetos de estudo diferentes: o comportamento individual e as práticas culturais. Além disso, enseja a possibilidade de se identificar um dos principais nichos de aplicação de sua proposta de uma unidade de análise específica para a cultura: as organizações, tomadas de início como sistemas representativos do âmbito empresarial, cujo eventual sucesso estaria na relação de dependência entre produto agregado e consequências culturais mantidas por um sistema receptor. O sistema glenniano rapidamente generalizou-se como possibilidade explicativa de quaisquer outras modalidades de conglomerados humanos, movidos por diferentes tipos de consequência. Neles, embora o termo "produto agregado" tenha permanecido o mesmo, seu significado se amplia de resultados físicos gerados pelo comportamento sincrônico dos indivíduos que compõem o grupo, para qualquer resultado que, de alguma forma, caracterize entrelaçamento consistente a ponto de constituir um padrão do grupo capaz de gerar consequências compartilháveis que mantêm a prática cultural.

A unidade de análise priorizada por Glenn (metacontingência) passou por reformulações desde 1986 (cf. 1988, 1991, 2004). Um resumo recente (Morford \& Cihon, 2013) sugere que:

\section{(1) Contingências Comportamentais}

Entrelaçadas (CCE) podem ser entendidas como contingências envolvidas em episódios sociais nos quais o comportamento de um organismo pode ter função discriminativa ou reforçadora para o comportamento de outro organismo (p. 5). Neste caso, a expressão original "interlocking" enfatiza a relação de dependência entre os comportamentos de ambos os organismos. Ou seja, embora cada organismo seja também controlado por contingências individuais, neste caso as contingências envolvidas requerem o comportamento de outro organismo como evento antecedente ou consequente. Assim, para Morford e Cihon (2013), são entrelaçadas "contingências operantes de duas ou mais pessoas, nas quais o comportamento de uma (ou o seu produto) atua como antecedente ou consequente para o comportamento de outra(s)" (p. 6). 
(2) Produto Agregado constitui-se, por exemplo, como o resultado físico produzido pelas contingências entrelaçadas. Exemplifique-se por um novo carro fabricado, cuja possibilidade de ser consumido por compradores - sistema receptor - depende de uma articulação única de comportamentos de distintos trabalhadores, passando pela concepção, pelos estudos de viabilização comercial, pela funcionalidade técnica e numerosos outros aspectos e instâncias. É de se notar, no entanto, que esse conceito tem sido estendido a outros exemplos significando a própria configuração de comportamentos de tal maneira articulados que possam resultar, apenas quando tomados conjuntamente, como prática cultural capaz de gerar resultados associados a reforçadores diversos.

(3) Consequência Cultural é constituída por um evento ambiental que ocorre temporalmente próximo (e posterior) a uma CCE e cuja ocorrência depende da sua emissão, de maneira análoga à relação de dependência entre a pressão à barra e a liberação de alimento. Não há uma separação estanque entre "produto agregado" e "consequência cultural". A lógica por detrás dessa díade conceitual reside na suposição de que, ao menos em alguns casos, o "produto agregado" possa não ser responsável pela seleção/manutenção de práticas culturais, ou seja, não atue como consequência reforçadora cultural. Ainda que seja produto consequente das contingências entrelaçadas, o produto agregado não possui em si função seletiva intrínseca. $\mathrm{O}$ caso das organizações empresariais citado amplamente na literatura (cf. Glenn \& Malott, 2004d) parece ser o exemplo ideal: o produto de uma fábrica de automóveis não é responsável pela manutenção das contingências entrelaçadas que constituem aquela "microcultura". Há a necessidade de um "sistema receptor" do produto agregado; esse sistema é responsável pelo fornecimento da "consequência cultural". Nesse caso, as concessionárias dedicadas à revenda de automóveis ao consumidor final pagam (i.e., mediante dinheiro, reforçador generalizado) pelos automóveis produzidos na fábrica.

(4) Metacontingência é uma unidade de análise que descreve relações entre eventos ambientais antecedentes, as CCEs e consequências culturais que alteram ou mantêm alguma dimensão mensurável das CCEs.

Naturalmente, o "sistema" glenniano ainda passa pelo processo natural de análises teóricas (e.g., Andery \& Sério, 2005; Glenn, Malott, Andery, Benvenuti, Houmanfar, Sandaker, Todorov, Tourinho, Vasconcelos, 2016; Gusso \& Kubo, 2007; Mattaini, 2004; Todorov, 2006) e testes de viabilização experimental, uma vez que, conquanto a Análise do Comportamento já tenha sido utilizada extensamente em situações culturais antes do advento das metacontingências, ainda é reduzida a literatura que usa dessa unidade conceitual em pesquisas e intervenções. Por essa razão, interpretações por vezes diferentes dos termos-chave do sistema são encontradas na literatura. De todo modo, para as finalidades deste ensaio, os argumentos centrais não serão afetados por eventuais minúcias que não alterem a lógica central da proposta de S. Glenn.

Breves dissensões - apesar do amplo reconhecimento da comunidade de analistas à contribuição de S. Glenn e M. Malott - têm sido encontradas na literatura, especialmente as publicadas no periódico até aqui mais conhecido da Análise Comportamental da Cultura, o Behavior and Social Issues. Nele, em 2006, Houmanfar e Rodrigues reconhecem a influência do materialismo cultural de Marvin Harris na concepção da unidade conceitual de metacontingência, registrando que, enquanto a análise do comportamento focalizava o indivíduo, o materialismo cultural focalizava a ação grupal. O que gera a possibilidade de que essa influência viesse acompanhada da exigência de manter como unidade de análise as ações grupais, garantindo que as consequências de práticas culturais sejam, de fato, dirigidas ao grupo como tal e não aos indivíduos que o compõem. Apesar de que a ação grupal resulte de comportamentos individuais no sentido de que estes são seu substrato essencial (Glenn, 1988), é importante notar que, no entanto, as duas disciplinas (Análise do Comportamento e Análise da Cultura), em última análise, possuiriam sua própria unidade de análise e seus próprios princípios. Para Glenn (2004), o fenômeno cultural não pode ser reduzido ao comportamento individual, no mesmo sentido em que o comportamento não pode ser reduzido à Fisiologia. Por oportuno, observe-se que, embora a comparação possa ter forte apelo à distinção entre práticas culturais e comportamento operante, não parece de todo pertinente pelo fato de que, na literatura, parece passar ao largo das reflexões dos analistas incorporar qualquer dos dois tipos de reducionismo.

De todo modo, Houmanfar e Rodrigues (2006) seguem com seu propósito de “... contribuir para um entendimento da interação interdisciplinar entre Análise do Comportamento e Materialismo Cultural e discutir um potencial refinamento dessa interação" (p. 14), mas, ao final, informam que a metacontingência "em sua forma atual é conceitualmente inconsistente, devido ao cruzamento de diferentes níveis de análise” (p. 29). Isso levanta uma questão crucial em relação à aparente confusão entre níveis de análise e processos distintos, quando se aborda o que a formulação de Skinner contém ao referir-se aos três níveis de variação e seleção e ao que caracterizaria fundamentalmente os processos comportamentais (especialmente no caso do operante).

\section{Níveis de análise e os três tipos de variação e seleção}

Vale recuperar, uma vez mais, a clássica proposição de Skinner sobre níveis de variação e seleção. $\mathrm{O}$ autor enfatiza em alguns textos (1945, 1961, 1969/1984a, 1981, 1990) sua sugestão sobre os tipos de variação e seleção que inspiram a lógica da análise de contingências: (1) A seleção natural, responsável pelo processo evolutivo e, consequentemente, pelo comportamento típico das espécies. A história evolutiva da espécie retrata a seleção de características genotípicas que aumentaram a probabilidade de sua sobrevivência. Para Skinner (1984b), uma consequência relevante é que os 
indivíduos que a compõem estarão preparados para um futuro que seja similar ao ambiente passado que os selecionou. É importante ressaltar, porém, que esse preparo não é necessariamente um dos elementos responsáveis pela seleção de uma dada característica, tal como, por exemplo, seria o caso da maximização da probabilidade de reprodução dos sujeitos que a possuem. A "similaridade" é, por certo, um conceito relativo, assim como a "regularidade" do ambiente é um tanto incerta. Diante dessa dinâmica e dentro de um largo espectro temporal, os comportamentos (e todas as características a eles relacionadas) da espécie que sejam funcionais para a sua adaptação ao ambiente acabam por reproduzir-se geração a geração; (2) Quando o ambiente não é estável por tempo suficiente para assegurar mudanças filogenéticas (e é este o caso de grande parte dos repertórios comportamentais da espécie humana), outra dimensão dos processos de variação e seleção está em jogo: trata-se da suscetibilidade do comportamento à seleção ontogenética, referida à história particular de interações de um membro da espécie durante o seu período de existência. Está aí presente, prioritariamente, o âmbito das relações individuais com o ambiente, ainda sem a concorrência complexa das situações comunitárias em que o comportamento das pessoas em grupo e as consequências compartilhadas articuladamente é que são responsáveis pela instalação, manutenção e extinção de condutas discretas. Nessa dimensão, torna-se clara a aproximação e complementaridade entre o modelo de seleção natural darwiniano e o processo de condicionamento operante skinneriano, haja vista que ambos envolvem seleção pelas consequências, ainda que por mecanismos diferentes; (3) O terceiro nível de variação e seleção implica contingências especiais mantidas por um ambiente social que, para Skinner (1981), representa a cultura. Note-se que o contexto da cultura, para Skinner, compõe-se de uma articulação indissociável entre comportamento e ambiente, no sentido de que as práticas culturais (que, no limite, são comportamentos das pessoas em grupo) e as dimensões (sociais, biológicas, químicas, porém todas, em última análise, referenciadas por alguma materialidade física) do contexto ambiental compõem o cenário vital para a existência de alguma sociedade. Observe-se que, embora o controle por consequências diretas se mantenha nos níveis mencionados em (2) e (3), neste último nível é o controle por regras que exerce um papel extremamente importante. Tal controle é, a um só tempo, econômico e funcional para manter a efetividade das práticas culturais a um "custo de aprendizagem" baixo o suficiente para ser viável.

$\mathrm{O}$ primeiro e o segundo níveis de seleção constituem bases importantes para a compreensão das atividades dos organismos, mas nosso interesse aqui está dirigido para além das dimensões filogenéticas e para além dos já tão bem estabelecidos princípios do comportamento operante que se sustentam na lógica da seleção ontogenética. Buscar similaridades e distinções entre contingências e metacontingências e, eventualmente, aceitar ou não esta ou aquela unidade de análise das práticas culturais implica explorar a terceira dimensão do processo de seleção em termos de seus conceitos e de seu alcance pragmático, mas não apenas isso: implica explorar alguns argumentos essenciais de Skinner e Glenn para a compreensão dos dois conceitos concorrentes. Ao lidar com práticas culturais, naturalmente, entendemos que estas requerem comportamento social, embora esses dois conceitos não necessariamente e sempre impliquem o mesmo arranjo de contingências. Desde 1953, Skinner conceitua o comportamento social como sendo "o comportamento de duas ou mais pessoas, uma em relação à outra ou, em conjunto, em relação a um ambiente comum" (1953/1967, p. 171). No comportamento social, portanto, outra pessoa deve estar envolvida, seja constituindo evento ou parte de evento diante do qual o organismo responde, seja constituindo a fonte de consequências que controlam o comportamento desse organismo. O comportamento social adquire dimensões mais complexas quando se passa ao âmbito das práticas culturais. Nelas, está implícita a repetição/replicação de comportamentos similares, coerentes, compatíveis, sincrônicos e/ou análogos pelos indivíduos componentes de um grupo, com especial ênfase no aspecto da funcionalidade para a produção de consequências para uma multiplicidade de pessoas. Outra dimensão das práticas culturais que ultrapassa o conceito de comportamento social (embora o incorpore) está na transmissão cultural de tais repertórios. Nesse sentido, um dado básico das práticas culturais é sua replicação dinâmica (porque, nesse processo, costumam sofrer alterações) intergeracional. Naturalmente, o fato de que algumas práticas culturais sejam - no logo prazo deletérias para a sobrevivência dos indivíduos que compõem uma cultura, não significa que deixem de ser práticas culturais ou que práticas culturais necessariamente mantenham como princípio a sobrevivência de todos os indivíduos que participam de determinada cultura, durante todo o tempo. A poluição industrial, sem dúvida, produz efeitos nocivos à saúde coletiva, mas, apesar disso, pode reproduzir-se por muito tempo como produto de uma prática cultural à custa de arranjos de contingências que proveem outras consequências reforçadoras importantes para quem assim procede (poluindo). Embora Skinner (1953/1967, 1981) reiteradamente mencione os "efeitos para o grupo", sempre é bom lembrar que tudo indica tratar-se de uma metáfora: o grupo não constitui organismo, de modo que não interage, ele próprio, com o ambiente. São os indivíduos que o compõem que são suscetíveis ao arranjo de contingências. Mas, naturalmente, nas práticas culturais existe uma relação inevitável de articulação necessária, por vezes uma dependência, entre comportamentos dos componentes do grupo e o contexto ambiental. Ou seja, as consequências que agem sobre o indivíduo selecionam padrões comportamentais particulares; entretanto, as consequências que atuam sobre os membros de um grupo como tal selecionam práticas culturais na medida em que estas, em última análise, também remetem aos comportamentos dos indivíduos, mas com uma especificidade distintiva: são tipicamente comportamentos entre si articulados responsáveis pela produção de 
consequências compartilhadas pelos membros do grupo. Esse é um dos sentidos pelos quais é possível falar de contingências entrelaçadas: os comportamentos operantes individuais dos membros do grupo são controlados por parâmetros de frequência, duração, intensidade ou outro tipo de medida compatível e funcional para a produção, em curto ou longo prazo, de contingências funcionalmente equivalentes para os participantes dessa comunidade.

É exatamente neste ponto - o do entrelaçamento de comportamentos e contingências - que se estabelece uma indagação relevante sobre a viabilidade maior ou menor de qualquer das unidades de análise: contingências ou metacontingências. Argumenta-se que o que é selecionado não é propriamente o comportamento dos indivíduos, mas o entrelaçamento de comportamentos, ou seja, um arranjo tal de uma ou mais classes de operantes que seja capaz de produzir uma consequência compartilhável. Na medida em que o entrelaçamento se daria apenas no âmbito cultural, o argumento prossegue defendendo que o que é selecionado é o padrão de práticas $d o$ grupo, sugerindo que os efeitos de seleção incidiriam sobre $o$ grupo. $\mathrm{O}$ argumento alternativo é o de que não há efeitos sobre o grupo, embora haja efeitos sobre o comportamento das pessoas em grupo. Nesse sentido, as consequências selecionariam comportamentos (que são sempre individuais), neste caso com funções discriminativas ou reforçadoras para outros membros de um grupo, obedecendo a um padrão específico em várias dimensões (temporal e topográfica, por exemplo) que gera consequências para esses indivíduos. Se se adota o primeiro conjunto de argumentos, supostamente se está frisando uma diferença quanto à natureza dos fenômenos sob análise, de modo que ao exame dos comportamentos individuais continuaria bastando o conceito de contingência, mas às práticas culturais se tornaria imprescindível outra unidade de análise, qual seja, a de metacontingência.

\section{Análise operante das práticas culturais}

Para melhor compreender essas diferenças categoriais é conveniente retornar à ideia skinneriana de níveis de variação e seleção. É fundamental notar que quando Skinner fala em níveis, está fazendo referência a âmbitos distintos (da espécie, do indivíduo e da cultura) e não a qualquer tipo de gradação. Trata-se, no entanto, de uma referência unívoca quanto ao processo subjacente em jogo: a seleção pelas consequências, que está presente nas dimensões filogenética, ontogenética e cultural. $\mathrm{O}$ selecionismo, de diferentes formas, é o traço transversal dessas três dimensões. Obviamente, sua ação se dá de maneiras distintas (por exemplo, respectivamente selecionando mutações, selecionando comportamentos, selecionando práticas culturais). Entretanto, quando nos deparamos com um representante qualquer da espécie humana, sabemos, por suas características biológicas, que ele pertence a essa espécie e que provavelmente resulta de uma extensa trajetória filogenética. Sabemos, adicionalmente, que durante sua trajetória temporal particular de vida (como indivíduo), possui uma história de interações necessariamente distinta e única, o que caracteriza seu contexto ontogenético. E, na sequência, sabemos que ele possui um caráter de pertencimento a grupos (ser brasileiro, ser psicólogo, ser apreciador de determinado tipo de música, ser militante partidário, ser aluno, ser professor). Como esse pertencimento apresentase dependente de uma história particular de interações, embora muitas das práticas e grupos de que participa sejam sincronicamente executadas com a mediação de outrem (no sentido de comportamento social atribuído por Skinner), seu repertório comportamental é sempre único.

É justamente no ponto de intersecção (ou de encontro?) entre os níveis ontogenético e cultural que se enraíza o questionamento sobre se estamos diante de fenômenos diferentes quanto à sua natureza ou se o terceiro nível constitui uma extensão natural do operante à instância coletiva, que pode ser entendida mediante a utilização da mesma unidade conceitual de análise de contingências. Se se trata de uma ampliação natural, uma vez que passamos a olhar para comportamentos mediados por outrem e, adicionalmente, para comportamentos sincrônicos que produzem consequências para vários indivíduos, então não parece plausível considerar retomando-se a reflexão inicial da busca por um modelo de explicação "elegante" - a necessidade de criação de novos conceitos explicativos para o âmbito das práticas culturais. Bastaria, nesse caso, como requereria o modelo machiano adotado por Skinner, estender o paradigma básico da contingência de três termos ao terceiro nível, tomando - isto sim - os comportamentos individuais de tal maneira arranjados que apenas desse modo pudessem se constituir numa prática cultural passível de algum tipo de seleção pelas consequências. Parece adequado aduzir que ao tratar de níveis de variação e seleção, não está implícita no modelo skinneriano qualquer possibilidade de classificação de cada qual como superior, inferior, menos ou mais importante. A separação feita por Skinner vinculase, apenas, ao tipo de arranjo de variáveis presentes em cada "nível". Note-se, adicionalmente, que no modelo de metacontingência, seja nesse conceito central ou nos de produto agregado, sistema receptor, contingências comportamentais entrelaçadas, a compreensão clara e a descrição precisa do processo cultural examinado sob a égide comportamental exige sempre e inevitavelmente um retorno aos termos singulares da contingência de três termos. Em outras palavras, para compreender "comportamentalmente" o que seja, por exemplo, "produto agregado", faz-se necessária sua descrição em termos funcionais (e, menos, "estruturais", como talvez a influência do materialismo cultural de Marvin Harris pudesse sugerir). Mais detalhadamente, nesse exercício de descrição funcional do sistema glenniano parece implícita e inevitável uma "redução" aos termos fundamentais da Análise do Comportamento presentes na contingência de três termos. Nesse sentido, um "sistema receptor", para além de ser aceito como uma "estrutura" social que apoie ou rejeite o resultado de certa prática cultural, precisa ser entendido em termos funcionais, o que exige respostas a questões mais básicas: quais são os possíveis reforçadores, como se estabelecem as relações de dependência entre o que é produzido comportamentalmente e as consequências 
sociais e assim por diante. Ou seja, a explicitação do "sistema de metacontingências" necessariamente se reporta à descrição funcional/relacional, em termos de eventos antecedentes, comportamento e eventos consequentes, da prática cultural e do respectivo contexto sob análise. Dito de outra maneira, reporta-se, mediante a denominação "metacontingências", não a um novo processo ou procedimento de análise, mas a uma descrição implícita e pormenorizada das contingências requeridas para o comportamento de indivíduos quando no âmbito do grupo. Apenas tal "configuração" de relações entre indivíduos e seu ambiente enseja o uso da expressão "práticas culturais".

Assim, se considerarmos pertinente o conteúdo citado em epígrafe, parece plausível entender que uma análise comportamental da cultura é possível mediante o uso do conceito de contingências. Não há "outro nível de análise" que não seja o do comportamento em sua relação com ambiente antecedente e consequente. O desafio está em descrever relações e estas, neste caso, dizem respeito a delinear com precisão que comportamentos (e quais seus padrões de entrelaçamento com os de outrem numa situação de grupo). De todo modo, mesmo que essa conclusão faça sentido, continua sendo muito importante a colaboração de autores como S. Glenn, com a proposição dos conceitos de metacontingência e seus complementares, uma vez que, mesmo não sendo conceitos genuinamente "novos", convidam os analistas a um aprofundamento das questões relativas a comportamento e cultura. $\mathrm{O}$ advento das metacontingências representa uma sinalização altamente relevante para as possibilidades de a Análise do Comportamento concretizar suas contribuições para práticas culturais cooperativas e solidárias, sobretudo a partir do emblemático convite apresentado por Glenn no seu texto de 1986, para que os analistas do comportamento comecem seu trabalho de planejamento cultural (mais do que dirigidos a irrealizáveis utopias), ficando atentos para os desafios do cotidiano contemporâneo.

Resta aos analistas, então, a tarefa de operacionalizar contingências no âmbito da cultura. Para isso, o próximo passo implica adotar alguns parâmetros orientadores do desdobramento do emprego da unidade de análise original no terceiro "nível" de variação e seleção. Esperam-se novas pesquisas revendo as conveniências respectivas de emprego de contingência ou metacontingência para análise de práticas culturais e sugerem-se alguns cuidados em relação a essa tarefa: (a) clareza conceitual, referindo-se à competência terminológica e operacionalidade dos conceitos utilizados para conduzir o analista à identificação inequívoca da realidade cultural/comportamental que pretende examinar; ou seja, em que medida a unidade conceitual permite identificação clara de instâncias ambientais e comportamentais nos termos apontados por Skinner em seu Are theories of learning necessary? (1950); (b) completude conceitual, referindo-se à avaliação e estimativa concretas da eventual referência presente no conceito estudado sobre as diversas variáveis que afetam a instância, evento ou relação estudada no contexto das práticas culturais; (c) alcance explicativo, referindo-se à avaliação do alcance da unidade conceitual com referência às complexas relações estudadas na análise comportamental da cultura; (d) simplicidade conceitual, referindo-se, em complemento à completude conceitual, à questão sobre em que medida os conceitos subsidiários associados ao de contingência exigem maiores ou menores condicionantes conceituais secundários para chegar a uma análise funcional da situação estudada; e (e) funcionalidade tecnológica, referindo-se à capacidade da unidade conceitual para abrangência prática em delineamentos culturais, com redução de obstáculos para aplicação.

\section{Precisamos da metacontingência? Uma situação- exemplo.}

Seguindo o padrão de grande parte da literatura sobre metacontingência, para tratar dessas questões adotaremos, para exemplificar, um caso hipotético e simplificado de microempresa de móveis formada por cinco funcionários/sócios, cada qual exercendo atividade distinta, mas todas relevantes para a manutenção da organização. Eis a sua configuração: (1) Comprador: responsável pela aquisição de matéria prima (madeiras específicas, ferramentas, etc.), deve entrar em contato com fornecedores, fazer orçamentos de preços e assegurar que as transações sejam realizadas de acordo com as leis ambientais; (2) Designer: responsável pela criação dos móveis "no papel”. É a pessoa que desenvolve o catálogo de produtos da microempresa, novos modelos de mesas, cadeiras, armários e assim por diante; (3) Artesão 1: responsável pela confecção dos móveis criados pelo designer. É quem transforma em objeto concreto as suas ideias, trabalhando diretamente com as madeiras, ferramentas de carpintaria, etc.; (4) Artesão 2: é também responsável pela confecção dos móveis, no entanto sua função especial é trabalhar com acabamentos (pinturas, marchetaria, etc.). Ou seja, enquanto o artesão 1 é responsável pela construção do móvel, o artesão 2 dedicase ao acabamento do produto; e (5) Vendedor: responsável pela venda dos móveis produzidos às lojas do ramo.

Levando-se em consideração o arcabouço conceitual em análise comportamental da cultura, diríamos que essa microempresa consiste em uma "microcultura". As contingências operantes associadas aos seus cinco funcionários/sócios estão entrelaçadas (exemplos de entrelaçamento serão apresentados a seguir), e o conjunto de contingências entrelaçadas cumpre a condição de caracterização das "práticas culturais" constituintes dessa microcultura. Há "produtos agregados" cuja produção depende inextricavelmente das contingências entrelaçadas: os móveis. As lojas cumprem o papel de "sistema seletor": pagam pelos móveis (produto físico agregado) e o montante recebido (dinheiro, reforçador generalizado), é responsável, em parte, pelo fortalecimento das práticas culturais associadas a essa microcultura. Avaliaremos, a partir deste exemplo, se a rede conceitual fundamentada na metacontingência seria de fato imprescindível para a compreensão da dinâmica interativa entre sujeitos participantes desse pequeno episódio simulado. 
Comecemos com um projeto específico dentro dessa microempresa. O designer decide desenvolver uma linha de poltronas de luxo usando como matérias primas jacarandá da Bahia e couro bovino. Ele questiona seu colega encarregado das compras se seria possível adquirir tais matérias primas. O comprador entra em contato com os fornecedores e busca o melhor preço da madeira e do couro. Dá o aval ao designer que, então, passa ao desenvolvimento das poltronas. Esse trabalho é realizado com a supervisão dos artesãos, responsáveis por guiar o designer na criação de modelos de poltronas que sejam possíveis de construir. Por fim, o vendedor é encarregado de pesquisar o interesse do mercado por poltronas feitas com tais materiais. Apresenta o portfólio com as poltronas criadas pelo designer aos compradores em potencial. Se houver interesse, o projeto é levado a cabo.

Pensado sob o ângulo do sistema glenniano, notase nesse breve exemplo a existência de "contingências entrelaçadas" constituintes de "práticas culturais" dessa "microcultura". O designer, por exemplo, pode apresentar um esboço de modelo de poltrona aos artesãos que, então, dizem ser impossível construí-lo com tal e qual característica. Esse feedback, por sua vez, faz com que o designer mude o seu projeto, adequando-o à possibilidade de construção. Os avais do comprador de matéria prima e do vendedor também são essenciais para a continuidade da criação dessa linha de poltronas. Desse modo, as contingências operantes entrelaçadas associadas aos funcionários/sócios da microempresa levam à produção final: as poltronas propriamente ditas. Este poderia ser o "produto agregado". Por mais que os sujeitos possam se sentir "realizados" ou "felizes" com tal feito, esse produto agregado não é responsável pela manutenção das práticas culturais associadas à construção dessa linha de poltronas. O retorno financeiro (dinheiro, reforçador generalizado) é a principal consequência reforçadora. Afinal, estamos lidando com uma empresa e, devido à própria natureza do negócio, é preciso que exista algum tipo de retorno financeiro para mantê-la existindo. A Figura 1 coloca de modo esquemático, alternativamente ao sistema glenniano baseado em metacontingências, uma análise de contingências atuando nessa microempresa.

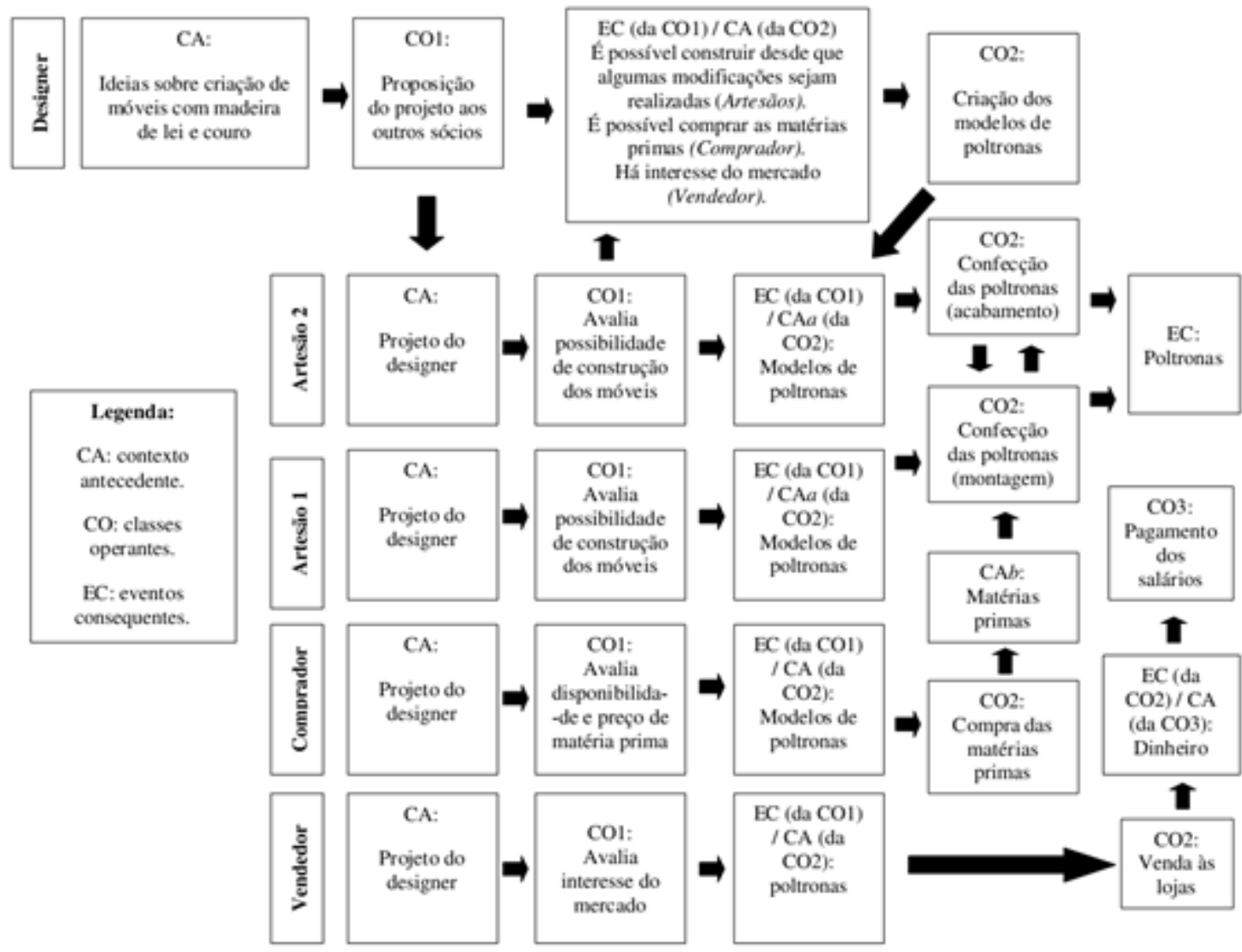

Figura 1. Contingências operando na microempresa de móveis.

Como o vendedor já havia checado o interesse dos compradores, a primeira leva de produção das poltronas é vendida sem problemas, resultando em retorno financeiro considerável (consequência reforçadora), este sim responsável pela manutenção das contingências entrelaçadas associadas a essa microempresa. Como consequência, há produção de nova leva de poltronas. Suponhamos, então, que posteriormente o vendedor encontre dificuldades: as lojas não estão mais interessadas. Apresentam diversos motivos, sendo o principal o alto 
preço do produto. Os funcionários/sócios estudam alternativas para diminuir o valor final do produto. $\mathrm{O}$ comprador de matérias primas sugere o jacarandá indiano, cujo custo é bem mais em conta em relação ao da Bahia, assim como o uso do couro sintético ao invés de couro de boi. A mudança de matérias primas resultou em queda do valor final de revenda e mais uma vez as lojas interessadas compraram a nova linha de poltronas, mantendo assim as práticas culturais das quais elas resultaram. Outro acontecimento possível: no meio do processo de produção dessa nova linha, o artesão responsável pelos acabamentos precisou se desligar da microempresa. $\mathrm{O}$ artesão ensinou as técnicas ao sujeito que foi contratado para ocupar o seu lugar. Dessa forma, as práticas culturais mantiveram-se relativamente estáveis, tendo os mesmos produtos como resultado, a despeito da substituição de sujeitos.

Talvez haja coerência em supor que esse breve exemplo seja compatível com o modelo de seleção cultural baseado no conceito de metacontingência. Todos os elementos estão ali: há "contingências entrelaçadas" que, quando vistas em conjunto, implicam "práticas culturais"; há "produto agregado", resultado que não seria possível a não ser como produto das contingências entrelaçadas e arranjadas mediante configuração e sequência específicas; há "consequência cultural" e "sistema receptor", responsáveis pela manutenção das práticas culturais envolvidas. Descrevemos também a possibilidade de troca de participantes sem a existência de mudanças significativas nas práticas culturais.

A questão que se coloca, porém, é outra: precisamos da metacontingência, de seus conceitos auxiliares e, mais importante, das pressuposições subjacentes ao modelo (por exemplo, a de que existiria um tipo ou processo diferente de seleção, que demandaria um nível distinto de análise e conceitos auxiliares, como os de produto agregado e sistema receptor) para explicar esse breve exemplo de práticas culturais? Provavelmente não. Note-se que a descrição das diversas atividades constituintes das práticas culturais dessa microempresa se deu no âmbito das contingências operantes associadas a cada funcionário/sócio da empresa. Até mesmo quando descrevemos a possibilidade da denominada "consequência cultural" (compra por parte das lojas, os "sistemas receptores"), o fizemos a partir de contingencias operantes associadas aos comportamentos do vendedor. $\mathrm{O}$ "sistema receptor", por exemplo, consiste, fundamentalmente, de um conjunto de possíveis lojas representado por pessoas, que são seus proprietários ou gerentes, capazes de decidir se compram ou não; em outras palavras, eles decidem pela liberação de reforçadores condicionados generalizados - dinheiro - na medida em que avaliem e aprovem os padrões das classes de operantes implicadas na concepção e construção das poltronas; ou seja, essa "entidade" denominada de "sistema receptor" seria, na verdade, uma forma abreviada, uma nomenclatura abrangente destinada a designar condições em que pessoas interagem e, no caso, reforçam ou não o comportamento de outras em função da aquisição ou não dos objetos que o comportamento destas produz. Por outro lado, a pessoa encarregada da venda avalia a possibilidade de comercializar o produto a ser desenvolvido. Ao confirmar o interesse das lojas, ele informa os outros membros que, então, dão continuidade ao projeto. A "consequência cultural" (isto é, o dinheiro, como reforçador condicionado generalizado, recebido pela venda) só faz sentido quando analisada à luz das contingências operantes individuais. Afinal, cada sujeito está ali como membro daquela microcultura por conta das consequências que se seguem de tal prática para si, individualmente, estando entre as mais importantes, possivelmente, o salário recebido ao final do mês.

Evidentemente, essa situação hipotética e arbitrária constitui apenas exemplo discreto da possibilidade concreta de análise de uma mesma situação utilizando qualquer dos dois "sistemas" de análise: o de Glenn ou o de Skinner, o de metacontingências ou o de contingências como instrumento de análise. $O$ que se revela nesse exercício é a possibilidade de manter a contingência de três termos, uma vez que esta se constitui na instância mais essencial e básica para análise do comportamento, independentemente da complexidade da configuração de entrelaçamento que esteja sendo examinada. Essa espécie de "retro-tradução" (ou seja, um retorno às contingências) revela não se tratar, o âmbito da cultura, de uma instância na qual as práticas culturais entrelaçadas constituem-se de outra natureza fenomênica, por mais aparentemente inexpugnável e complexo que possa apresentar-se no contexto do grupo. Os pontos centrais continuam sendo o comportamento e a seleção pelas consequências, legados que permitem, em tese, ainda sob o paradigma da contingência de três termos, a análise do comportamento no contexto cultural. Por essa via, há indícios importantes de que o sistema conceitual de Glenn seja plenamente redutível, funcionalmente, à contingência de três termos, instrumento aparentemente irrenunciável da proposta skinneriana.

Em contrapartida, reitera-se inegável a importância das reflexões de Glenn, assim como dos autores que seguiram com o seu projeto, desenvolvendo análises teóricas, aplicadas e análogos experimentais, para a revitalização da análise do comportamento social e das práticas culturais. O trabalho de Glenn e colaboradores tem um papel altamente relevante, seja por demarcar aspectos centrais a serem analisados quando se passa ao terceiro "nível" de variação e seleção, seja por ter instrumentalizado o campo da pesquisa em Análise Comportamental da Cultura. Paralelamente, embora elemento contributivo para um revigoramento das iniciativas comportamentalistas na análise comportamental da cultura, o advento do conceito de metacontingência parece requerer do analista que se detenha na consideração do tipo de propositura científico-instrumental pretendida para a Análise do Comportamento. Com Skinner e os que o seguiram, essa condição é a de uma ciência natural estreitamente vinculada ao âmbito da Biologia. Como tal, um dos requisitos no seu trabalho de análise de fenômenos naturais é a utilização de princípios explicativos simples (não necessariamente simplistas) e essenciais, como parece o caso do conceito de contingência. Se o desenvolvimento da pesquisa em Análise Comportamental 
da Cultura se mostrar igualmente viável (comparativamente ao sistema que inclui metacontingência, produto agregado, consequência cultural e sistema receptor) com a utilização da contingência de três termos, parece que essa seria a opção "natural" a ser escolhida. Apenas o desenvolvimento de pesquisas por tempo razoável poderá responder positiva ou negativamente a essa questão.

Interessante notar que a hipótese de uma resposta positiva incluirá o fato decorrente de que, em tese, todo "experimento cultural" ou "análogo experimental de cultura" desenvolvido mediante a unidade de análise da metacontingência necessariamente teria que "dar certo", no sentido de apresentar resultados compatíveis com os princípios essenciais da Análise do Comportamento decorrentes da pesquisa experimental que até aqui tem corroborado a funcionalidade da contingência de três termos em milhares de situações diferentes. Nesse sentido, a metacontingência "recapitularia" a contingência e seria desta apenas um corolário prático e, não, uma inovação conceitual sem a qual não pudesse ser feita uma análise comportamental de práticas culturais, estas consideradas uma nova espécie de fenômeno no âmbito das relações entre indivíduo e ambiente.

Resta considerar que, embora por vezes se pense a cultura como fenômeno exclusivamente humano, por constituir-se de forma que sua complexidade comumente associa-se à mediação do comportamento verbal, o fato é que o âmbito do grupo e o sincronismo interindividual não são determinantes de uma natureza comportamental diversa ou sui generis e controlada por uma lógica distinta da seleção por consequências própria do âmbito ontogenético. O que se passa é que, muito menos que tratar-se de outro fenômeno ou de fenômeno de outra natureza, trata-se de um arranjo de contingências diferente, especialmente implicando entrelaçamento de comportamentos como configuração essencial para o estabelecimento de consequências. Além disso, o que há de "especial" na cultura é, para além da mediação por outrem, o papel central do comportamento verbal e a presença constante do controle por regras, além das questões típicas das consequências de longo prazo, em comparação com as de curto prazo. Descrever cada qual dessas condições e variáveis nas suas relações é parte o trabalho em Análise Comportamental da Cultura, que busca esclarecer, de modo direto e econômico, o arranjo, a configuração, a complexidade do design das práticas e as consequências que as mantêm.

\section{REFERÊNCIAS}

Andery, M. A., \& Sério, T. M. (2005). O conceito de metacontingências: afinal, a velha contingência de reforçamento é insuficiente? In J. C. Todorov, R. C. Martone, \& M. B. Moreira (Org.), Metacontingências: comportamento, cultura e sociedade (pp. 149-159). Santo André: ESETec Editores Associados.

Barrish, H., Saunders, M., Montrose, M. W. (1969). Good behavior game: effects of individual contingencies for group consequences on disruptive behavior in a classroom. Journal of Applied Behavior Analysis, 2(2), 119-124.

Bushell, D., Wrobel, P. A., Michaelis, M. L. (1968). Applying "group" contingencies to the classroom study behavior of preschool children. Journal of Applied Behavior Analysis, 1(1), 55-61.

Coyne, P. D. (1978). The effects of peer tutoring with group contingencies on the academic performance of college students. Journal of Applied Behavior Analysis, 11(2), 305-307.

De Rose, J. C. C. (1993). Classes de estímulos: implicações para uma análise comportamental da cognição. Psicologia: Teoria e Pesquisa, 9, 283-303.

Fantino, E. (Ed.). (1988). A celebration of the Behavior of Organisms at fifty [Special Issue]. Journal of Experimental Analysis of Behavior, 50, 2.

Glenn, S. S. (1986). Metacontingencies in Walden Two. Behavior Analysis and Social Action, 5(1), 2-8.

Glenn, S. S. (1988). Contingencies and metacontingencies: Toward a synthesis of behavior analysis and cultural materialism. The Behavior Analyst, 11, 161-179.

Glenn, S. S. (1991). Contingencies and metacontingencies: Relations among behavioral, cultural, and biological evolution. In P. A. Lamal (Ed.) Behavior Analysis of Societies and Cultural Practices (pp. 39-73). Washington, DC: Hemisphere.

Glenn, S. S. (2003a). Operant contingencies and the origin of cultures. In K. A. Lattal \& P. N. Chase (Ed.), Behavior Theory \& Philosophy (pp. 223-242). New York: Kluwer/Academic Press

Glenn, S. S. (2003b). Selección em dos niveles em la evolución de la ciencia. Revista Latinoamericana de Psicologia, 35(3), 281-288.

Glenn, S. S. (2004). Individual behavior, culture, and social change. The Behavior Analyst, 27(2), 133-151.

Glenn, S. S., Malott, M. E., Andery, M.A.P.A., Benvenuti, M., Houmanfar, R. A., Sandaker, I., Todorov, J. C., Tourinho, E. Z., Vasconcelos, L. A. (2016) Toward consistent terminology in a Behaviorist approach to cultural analysis. Behavior and Social Issues, 25, 1127.

Glenn, S. S., Malott, M. E. (2004a). Are operant principles sufficient to understand organizations? Reply do Salzinger. Behavior and Social Issues, 13(1), 143-144.

Glenn, S. S., Malott, M. E. (2004b). Are operant principles sufficient to understand organizations? Reply do Salzinger. Behavior and Social Issues, 13(1), 143-144.

Glenn, S. S., Malott, M. E. (2004c). Behavioral and cultural classifications: Reply to Mattaini. Behavior and Social Issues, 13(1), 131-133.

Glenn, S. S., Malott, M. E. (2004d). Complexity and selection: Implications for organizational change. Behavior and Social Issues, 13(1), 89-106.

Glenn, S. S., Malott, M. E. (2004e). On conceptual challenges: Reply to Hayes and Houmanfar. Behavior and Social Issues, 13(1), 112-115.

Glenn, S. S., Malott, M. E. (2004f). Organizations and institutions: Reply to Ulman. Behavior and Social Issues, 13(1), 152-154. 
Glenn, S. S., Malott, M. E. (2004g). Rules and metacontingencies: Reply to Sandaker. Behavior and Social Issues, 13(1), 152-154.

Glenn, S. S., Malott, M. E. (2005). Challenges to large scale change: Reply to Pennypacker. Behavior and Social Issues, 13(2), 138-139.

Gusso, H. L., \& Kubo, O. M. (2007). O conceito de cultura: afinal, a "jovem" metacontingência é necessária? Revista Brasileira de Terapia Comportamental e Cognitiva, 9(1), 139-144.

Houmanfar, R., \& Rodrigues, N. J. (2006). The metacontingency and the behavioral contingency: points of contact and departure. Behavior and Social Issues, 15, 1330 .

Holland, J. G. (1974). Servirán los princípios conductuales para los revolucionários? In F. S. Keller, \& E. Ribes (Ed.), Modificación de conducta: aplicaciónes a la educación (pp. 265-281). México: Trillas.

Lamal, P. A. (1991). Behavioral Analysis of Societies and Cultural Practices. New York: Hemisphere Publishing Corporation.

Lamal, P. A. (1997). Cultural contingencies: Behavior analytic perspectives on cultural practices. Westpot, CT, USA: Greenwood Publishing Group, Inc.

Lloyd, J. W., Eberhardt, M. J., Drake Jr., G. P. (1996). Group versus individual reinforcement contingencies within the context of group study conditions. Journal of Applied Behavior Analysis, 29(2), 189-200.

Lopes Jr., J., Matos, M. A. (1995). Controle pelo estímulo: aspectos conceituais e metodológicos acerca do controle contextual. Psicologia: Teoria e Pesquisa, 11, 33-39.

Mattaini, M. (2004). Systems, metacontingencies, and cultural analysis: are we there yet? Behavior and Social Issues, 13, 124-130.

McMichael, J. S., Corey, J. R. (1969). Contingency management in an introductory psychology course produces better learning. Journal of Applied Behavior Analysis, 2(2), 79-83.

McSweeny, A. J. (1978). Effects of response cost on the behavior of a million persons: charging for directory assistance in Cincinnati. Journal of Applied Behavior Analysis, 11(1), 47-51.

Marr, M. J. (2003). A still great voice: The golden sovereignty of Science and Human Behavior. Journal of the Experimental Analysis of Behavior, 80(3), 311312 .

Morford, Z. H., Cihon, T. M. (2013). Developing an experimental analysis of metacontingencies: considerations regarding cooperation in a four-person prisoner's dilemma game. Behavior and Social Issues, 22, 5-20.

Pigott, H. E., Fantuzzo, J. W., Clement, P. W. (1986). The effects of reciprocal peer tutoring and group contingencies on the academic performance of elementary school children. Journal of Applied Behavior Analysis, 19(1), 93-98.

Salzinger, K. (2004). Life is complicated; Analysis should be simple. Behavior and Social Issues, 13(1), 140-142.
Sidman, M. (1986). Functional analysis of emergent verbal classes. In T. Thompson \& M. D. Zeiller (Ed.), Analysis and integration of behavioral units (pp. 213245). Hilsdale, N.J. Erlbaum.

Skinner, B. F. (1945). The operational analysis of psychological terms. Psychological Review, 52, 270277.

Skinner, B. F. (1948). Walden Two. New York: Macmillan.

Skinner, B. F. (1950). Are Theories of Learning Necessary? Psychological Review, 57, 193-216.

Skinner, B. F. (1961). The design of cultures. Daedalus, 90(3), 534-546.

Skinner, B. F. (1966) Contingencies of reinforcement in the design of a culture. Behavioral Science, 11, 159166.

Skinner, B. F. (1967). Ciência e comportamento humano. Brasília, UNB. (Obra original publicada em 1953).

Skinner, B. F. (1978). Reflections on behaviorism and society. Englewood Cliffs, New Jersey: Prentice-Hall, Inc.

Skinner, B. F. (1981). Selection by consequences. Science, 213, 501-504.

Skinner, B. F. (1984a) Contingências de reforço: Uma análise teórica. São Paulo: Editora Abril. (Obra original publicada em 1969).

Skinner, B. F. (1984b). The evolution of behavior. Journal of the Experimental Analysis of Behavior, 41(2), 217221.

Skinner, B. F. (1988). Comments. In A. C. Catania, \& S. Harnad (Ed.), The selection of behavior: the operant behaviorism of B. F. Skinner: comments and consequences. New York: Cambridge University Press. (Obra original publicada em 1984).

Skinner, B. F. (1986). Contingencies of reinforcement in the design of a culture. Behavioral Science, 11, 159166.

Skinner, B. F. (1990). Can psychology be a science of mind? American Psychologist, 45(11), 1206-1210.

Souza, D. G. (1997). A evolução do conceito de contingência. In R. A. Banaco (Org.) Sobre Comportamento e Cognição - Aspectos teóricos, metodológicos e de formação (pp. 88-105). Santo André: ARBytes Editora.

Todorov, J. C. (2006). The metacontingency as a conceptual tool. Behavior and Social Issues, 15, 92-94.

Zimmerman, E. H., Zimmerman, J., Russell, C. D. (1969). Differential effects of token reinforcement on instruction-following behavior in retarded students instructed as a group. Journal of Applied Behavior Analysis, 2(2), 101-112. 